\title{
Correspondence
}

\section{Economic Space Transportation}

I WAS very interested by T. W. Smith's article "An Approach to Economic Space Transportation" in the August Journal 1966, which I think has many stimulating ideas of real value. It seems to me that there are a number of possible modifications or extensions of the author's proposals, and I should like his comments on two which I think might be worthwhile. No doubt, the work he has done could throw light on their practicability.

The first point concerns air-breathing boosters. These are discussed early in the article, and it is concluded that they are too heavy and too slow. I should like to know whether the author has considered adding a rocket motor to an air-breathing first stage. The air-breathing engines would be used up to their maximum speed and then shut down, and a rocket motor taking over would propel the vehicle up to separation speed. Simple sums suggest that such a mixed powerplant first stage is quite promising; for example a hydrogen-fuelled vehicle with a deadweight fraction of $40 \%$ using air-breathing engines up to $7000 \mathrm{ft} / \mathrm{sec}$ and a rocket motor for further boost could boost a $16 \%$ payload to about $12000 \mathrm{ft} / \mathrm{sec}$ (see Fig. 1 of the present writer's "Boost Glide Vehicles for Long Range Transport" in the July Journal 1965). This is $5000 \mathrm{ft} / \mathrm{sec}$ faster than "Mustard's" staging velocity and is probably fast enough for a re-usable upper stage to boost a useful payload into orbit. An expendable rocket second stage would not then be necessary. In effect, this vehicle is a compromise between a rocket first stage, with its high fuel fraction, and an airbreathing first stage, with its very advanced engines and heavy structure. However, these conclusions are very tentative, and detailed design could well show hidden snags.

The second question I should like to ask concerns the proposed development programme for "Mustard". Using the ground rules suggested by the author we have a choice of three launch systems for an early aerospace transporter:-

1. "Mustard".

2. Tandem two-stage rocket.

3. Air-breathing, or mixed powerplant first stage and a re-usable rocket upper stage.

Now all of these systems include a similar type of vehicle, namely a hydrogen-fuelled re-usable rocket booster of lifting body layout. This is the basic "Mustard" module and the upper stage of the other two systems. So would it not be sensible to make such a vehicle for research purposes first? The information gained would be used to help choose one of the three systems and the vehicle could then be modified and refined to form part of that system. The first objection would, no doubt, be that the research vehicle would be expensive and have no immediate use. However, could it not also be designed for use as a reusable first stage booster for launching a small payload into orbit, using conventional upper stages? The design requirements for a re-usable first stage are less severe than for "Mustard", because for a re-usable two-stage system the velocity increments of each stage must add up to satellite speed. This means that at least one of the stages must have a velocity increment at least half satellite speed, which in turn requires a definite combination of structural and propulsive efficiency for a re-usable stage. However, if the upper stage is expendable, the critical reusable lower stage can now have a velocity increment less than half satellite speed, thus, relaxing its design requirements. For example a re-usable lower stage with a deadweight fraction of $25 \%$ and a specific impulse of $420 \mathrm{sec}$ (compared with "Mustard's" $17 \%$ and $436 \mathrm{sec}$ ) could launch a respectable $10 \%$ payload to about $11000 \mathrm{ft} / \mathrm{sec}$, whereas, if "Mustard" had such a crude structure and propulsion, it could not achieve satellite speed at all, let alone launch a useful payload. Thus the suggested vehicle could be built more crudely than "Mustard" and hence more cheaply.

My suggestion then is to build a "Battleplate Mustard" as a re-usable, first-stage booster. It could be the next step after the lifting-body research glider and the re-entry research vehicle proposed by the author. It would be a VTO hydrogen-fuelled rocket vehicle of "Mustard" shape, but using cruder structures and propulsion. Each time it was used as a first stage booster it would save the production cost of an equivalent expendable booster, and so, after enough launches (probably about 100 ) it would save its own development cost. In addition this vehicle could be used for research leading to an Aerospace Transporter and could eventually be refined and used as part of that Aerospace Transporter. A further possible intermediate use would be for orbital research, by launching it into orbit with a conventional expendable lower stage. At first sight this would seem to be a promising extension of the author's proposals, and I should be very interested in his comments.

21 st September 1966.

D. M. AshFoRD, Graduate

$R$ EFERENCE 1 summarises a large body of work in a comparatively small compass, so although much of the information which has a bearing on Mr. Ashford's comments is, in fact, given in the text, the detail has probably suffered by compression.

With regard to the combined rocket-air-breathing first stage with hydrogen fuel, the structural fraction is normally higher for a hydrogen-fuelled than for a kerosine-fuelled aircraft because the relationship of calorific value to tank volume is adverse and because, in addition, the hydrogen tanks need an extra weight of insulation. That being so, the use of hydrogen does not substantially improve the situation shown for the rocket-boosted air-breather in Fig. 8.

Comparing the requirements of a recoverable upper stage launched at Mach number 12.0 (Fig. 13) with the carrying capacity of the rocket-boosted air-breather at Mach 7 (Fig. 8) it is clear that our studies offer very little prospect of usefully launching a single recoverable upper stage by this means.

With regard to the research programme it is agreed (Fig. 29) that a Mustard module represents a common element between competing launching systems, but a boiler plate research vehicle would conflict unacceptably with objective (c), that engineering problems unrelated to the goal-in-view should be strenuously avoided. Again, a conclusion that can be drawn from ref. 2 for instance, is that a multiplicity of different systems is a luxury.

Anything that adds to the versatility of the prime unit should be examined, of course, but the criterion should not be that it is technically feasible or has-simply an interesting performance, but whether it is worth doing overall. I suspect that major modification leading to virtually a new vehicle do not satisfy this criterion.

1. SмIтH, T. W. An Approach to Economic Space Transportation. Journal of the Royal Aeronautical Society, August 1966.

2. Derbyshire, T., ClegG, W. B. and Smith, T. W. Economic Space Transportation: Thoughts on Mission, Size and Sensitivity. Journal of the Royal Aeronautical Society, September 1966.

10th October 1966.

T. W. SMITH 